\title{
X-RAY COMPUTED TOMOGRAPHY EVALUATION OF INTRAMUSCULAR FAT CONTENT IN HUNGARIAN SIMMENTAL CATTLE
}

\author{
G. Hollón ${ }^{a *}$, B. HútH ${ }^{a}$ I. Hollóa and I. AnTON ${ }^{b}$ \\ aFaculty of Agricultural and Environmental Sciences, Kaposvár University, H-7400 Kaposvár, Guba S. utca 40. \\ Hungary \\ bNARIC-Research Institute for Animal Breeding, Nutrition and Meat Science, H-2053 Herceghalom, \\ Gesztenyés út 1. Hungary
}

(Received: 27 September 2017; accepted 5 December 2017)

\begin{abstract}
Intramuscular fat content (marbling) is an economically important factor in many beef carcass classification systems. The aim of this study was to evaluate marbling of longissimus muscle with different methods (USDA marbling score, image analysis of X-ray computed tomography scans, and conventional method), moreover it was aimed to establish the relationship between marbling traits and SEUROP conformation and fat score. Bulls $(n=46)$ were slaughtered at an average weight of $536 \pm 126 \mathrm{~kg}$ and an average age of $646 \pm 437$ days. The average growth rate of bulls was $955 \mathrm{~g} \mathrm{day}^{-1}$, the average chemical fat content of longissimus varied between 2.3 to $5.0 \%$ in fat classes. The intramuscular fat content on CT-scans closely correlated with chemical fat content $(\mathrm{r}=0.9)$. The highest frequency of USDA marbling score was "small" (55.2\%), followed by "slight" (25.5\%), "modest" (17\%), and "moderate" (2.1\%). Bulls with higher growth rate had lower CT-measured marbling traits in longissimus muscle $(\mathrm{r}=-0.4--0.5)$. The CT scans of longissimus muscle can be used for the evaluation of marbling in Hungarian Simmental cattle. The SEUROP conformation and fat score have no relationship with marbling traits.
\end{abstract}

Keywords: beef, intramuscular fat, marbling traits

Among many beef quality traits marbling is one of the most important quality characteristics of meat demanded by consumers (Platter et al., 2005; Morales et al., 2015). According to TROY and co-workers (2016), marbling not only provides higher eating quality of beef but also contains higher level of polyunsaturated fatty acids (PUFA) and monounsaturated fatty acids (MUFA) compared to other fats in beef. As a consequence, this determination and analysis of marbling plays an important role in the quality evaluation of meat. Marbling score is a component of several beef quality grading systems in the world including the United States, Japan, and Australia. It refers to visible fat found between muscle fibre bundles within the longissimus muscle. Marbling score is assessed subjectively (visual appraisal) by a grader during the process of assigning beef quality grade. Chemical analysis is another conventional method for meat marbling evaluation, and it has been widely used as a standard method for the accurate determination of intramuscular fat content. The intramuscular fat simply quantifies the amount (percent) of fat within the muscle, but marbling score considers amount,

* To whom correspondence should be addressed.

E-mail: hollo.gabriella@sic.ke.hu

This is an open-access article distributed under the terms of the Creative Commons Attribution-NonCommercial 4.0 International License (https://creativecommons.org/licenses/by-nc/4.0/), which permits unrestricted use, distribution, and reproduction in any medium for non-commercial purposes, provided the original author and source are credited, a link to the CC License is provided, and changes - if any - are indicated. 
distribution, and texture of fat, too. It is recognized that the distribution and size of marbling particles are relevant for meat quality (FERGUSON, 2004).

In Europe, neither intramuscular fat level nor other meat quality traits have been introduced into SEUROP based grading system. However, in order to meet the increasing consumer demands for improved beef quality, these expectations have become relevant. Nowadays, several innovative instrumental methods are being applied in meat industry in order to realise the rapid and on-line evaluation of marbling degree. These are mainly spectroscopic methods (NIR, NMR) but several imaging techniques are also known, such as computer image analysis (IRIE \& COHIRA, 2012), X-ray computed tomography (NADE et al., 2005; Holló et al., 2007; NAvajas et al., 2009; Frisullo et al., 2010; FonT-I-Furnols et al., 2014), and magnetic resonance imaging (LEE et al., 2015) measurements.

The aim of this study was to evaluate marbling traits of longissimus thoracis muscle with different methods: USDA marbling score, intramuscular fat content (IMF) by image analysis of X-ray computed tomography (CT) scans, and by conventional analytical method in order to investigate possible relationship between methods and to determine the effect of SEUROP conformation/fat score on the intramuscular fat level.

\section{Materials and methods}

Bulls ( $\mathrm{n}=46)$ were slaughtered at an average weight of $536 \pm 126 \mathrm{~kg}$ and an average age of $646 \pm 437$ days. The overall data represented a wide range of slaughter weights $(351-767 \mathrm{~kg})$. At slaughter, bulls were stunned with a captive bolt gun and killed by exsanguination. The following traits were recorded at slaughter: slaughter weight, hot carcass weight, and EU classification data. Carcasses were assessed by trained operator for conformation (an 18 point scale: scale 1 (poorest) to 18 (best)) and fatness (a 15 point scale: scale 1 (leanest) to 15 (fattest)) according to EU beef carcass classification scheme with the use of subclasses. After $24 \mathrm{~h}$, chilled samples were taken from the right half carcass at the 12th rib. USDA marbling score was assessed visually at the cut surface of the 12th ribeye and was classified into one of ten different degrees; from practically devoid to abundant. CT-examination of 12 th rib cuts was performed 3 days post mortem at the Institute of Diagnostic Imaging and Radiation Oncology of Kaposvár University. Scans were executed by using a 16-slice CT system (Siemens Somatom Sensation Cardiac, slice thickness: $5 \mathrm{~mm}, 120 \mathrm{kV}$ ). The average numbers of cross-sectional images were 13 for the 12 th rib, the number of scans varied from 12 to 15 scans, depending on the size of rib cut. On each scan, the longissimus muscle area as ROI (region of interest) was selected by manual method. Image analysis was performed by thresholding segmentation with the usage of MANGO $(3.8,2016)$ software. MANGO is multi image analysis software package, originally developed for medical image analysis; easy to use and provides useful options to display, edit, analyse, process, and save images. For the evaluation of IMF in longissimus muscle HU values between $-200-+20$ was used. Volumetric tissue content and tissue area of fat and muscle were determined. After CT examination, samples were transported to the Analytical Laboratory of the University. After removing surface fat, lipid content of muscle (IMF) was determined gravimetrically by Soxhlet method, using petroleum ether as solvent.

Data were statistically analysed by ANOVA using IBM SPSS 20.0 software. We compared mean values between main SEUROP fat grades $(1,2,3)$. Tukey's test was used to compare differences between mean values at a 5\% level of significance. All results are given 
in tables as mean and standard deviations and Pearson's correlation of intramuscular fat measured with different methods beside other estimated carcass and slaughter traits. The root mean square error and $\mathrm{R}^{2}$ for the regression models were determined.

\section{Results and discussion}

The European grading system primarily focuses on yield estimation, which is based on describing carcass conformation (S: superior muscled, $\mathrm{U}, \mathrm{R}, \mathrm{O}$, and $\mathrm{P}$ : very poorly muscled) and external fat level (from 1: very lean to 5: very fat) (Polkinghorne \& Thompson, 2010). However, the European grading system does not provide any quality-related information. Table 1 summarises the carcass and longissimus muscle traits according to SEUROP fat classes. The average hot carcass weight was $294 \mathrm{~kg}$, and there was a significant difference between fat grades. It seems that carcass weight increased with fat grade. Mean values of SEUROP conformation grade in fat classes varied from $4.2(\mathrm{O} 0)$ to 7.4 (R0). Higher fat grade was paired with significantly more favourable conformation grade. The average live weight growth rate and the net carcass gain of bulls were $955 \mathrm{~g} \mathrm{~d}^{-1}$ and $519 \mathrm{~g} \mathrm{~d}^{-1}$, respectively. There were no significant differences between SEUROP classes for these traits, but the growth rate tended to be higher in higher fat grades.

Table 1. Carcass and longissimus muscle traits among SEUROP fat grade

\begin{tabular}{lccccc}
\hline Traits & \multicolumn{5}{c}{ SEUROP fat grade } \\
& $1(\mathrm{n}=10)$ & $2(\mathrm{n}=26)$ & $3(\mathrm{n}=10)$ & Overall mean & P-value \\
\hline CARCASS & & & & & \\
Hot carcass weight, $\mathrm{kg}$ & $195.4 \pm 26.9$ & $291.0 \pm 60.3$ & $412.2 \pm 137.2$ & $293.7 \pm 84.4$ & $* * *$ \\
SEUROP muscle grade $(1-15)$ & $4.2 \pm 2.5$ & $5.6 \pm 1.4$ & $7.4 \pm 0.6$ & $5.7 \pm 1.6$ & $* *$ \\
Net carcass gain, $\mathrm{g} \mathrm{d}^{-1}$ & $443 \pm 209$ & $519 \pm 123$ & $597 \pm 144$ & $519 \pm 137$ & $\mathrm{NS}$ \\
Live weight gain, g d $^{-1}$ & $882 \pm 422$ & $947 \pm 215$ & $1088 \pm 330$ & $955 \pm 252$ & $\mathrm{NS}$ \\
\hline LONGISSIMUS & & & & & \\
Marbling score, USDA & $1.8 \pm 0.5$ & $1.9 \pm 0.8$ & $2.2 \pm 0.8$ & $2.0 \pm 0.7$ & $\mathrm{NS}$ \\
Intramuscular fat, \% & $5.0 \pm 2.8$ & $2.3 \pm 1.6$ & $4.1 \pm 1.8$ & $2.8 \pm 1.9$ & $* *$ \\
Average CT value, HU & $61.2 \pm 8.5$ & $65.4 \pm 3.8$ & $61.2 \pm 4.3$ & $64.5 \pm 4.7$ & $*$ \\
CT fat content, \% & $3.8 \pm 3.3$ & $1.1 \pm 1.0$ & $2.9 \pm 2.4$ & $1.9 \pm 1.5$ & $* *$ \\
CT muscle content, \% & $95.9 \pm 3.4$ & $97.9 \pm 1.7$ & $96.4 \pm 2.2$ & $97.5 \pm 2.1$ & $*$ \\
CT fat area, mm ${ }^{2}$ & $2629 \pm 1264$ & $891 \pm 183$ & $1832 \pm 313$ & $1176 \pm 599$ & $*$ \\
CT fat volume, mm $^{3}$ & $13143 \pm 6309$ & $4453 \pm 913$ & $9159 \pm 1562$ & $5878 \pm 2989$ & $*$ \\
\hline
\end{tabular}

*: $\mathrm{P}<0.05 ; * *: \mathrm{P}<0.01 ; * * *: \mathrm{P}<0.001 ;$ NS: not significant

Marbling is an economically important factor in many beef carcass classification systems such as in USDA (United States Department of Agriculture). The USDA quality grades are used to predict the palatability of meat from a beef carcass, using carcass physiological maturity and marbling (USDA, 1997), moreover, instrument grading for determining USDA quality grades of beef carcasses was accepted in 2006 by the USDA (USDA, 2006). 
SEUROP fat grades differed significantly for the examined marbling traits, except for USDA marbling score. The highest frequency of USDA marbling score was "small" (55.2\%), followed by "slight" (25.5\%), "modest" (17.2\%), and "moderate" (2.1\%). The highest USDA marbling scores were given for bulls belonging to fat class " 3 ".

The lipid content also plays an important role on the juiciness of beef. The decrease in intramuscular lipid content can also reduce tenderness (THOMPson, 2004). A minimum amount of intramuscular fat is needed for flavour to be expressed, and to achieve acceptable consumer satisfaction is about $3 \%$ to $4 \%$ for beef (HocQuetTe et al., 2010). The chemical fat content of longissimus varied between 2.3 to $5.0 \%$ in fat classes, whereas the maximum and minimum value of chemical fat content was 0.6 and $7.9 \%$, respectively. ENDER (1997) reported an average value of IMF content of $2.2 \%$ in European breeds, with the most common span of minimum (1.2\%) and maximum (3.2\%) values being $2 \%$. According to our results, higher intramuscular fat level was found in lower conformation classes. Previously, NogALSKI and co-workers (2013) found that carcass classification of fat classes in line with SEUROP system showed no differences between carcasses suggesting a similar intramuscular fat content. The SEUROP system may adequately describe carcass muscling characteristics, but it does not predict eating quality, especially marbling (BonNy et al., 2013). Marbling has been widely used as a major factor in predicting eating quality, because higher intramuscular fat is considered to improve eating quality traits (HOCQUETTE et al., 2010).

Therefore, it would be useful to be able to determine the intramuscular fat content of a cut or muscle by a rapid, non-destructive method.

Similar to chemical fat content, CT fat content was the highest in fat class" 1 ". On CT scans, the lower density tissues such as fat present lower (usually negative) Hounsfield values and darker colours than the higher density (usually positive Hounsfield values) tissues such as lean tissue and bone. In agreement with this, the higher fat content in longissimus muscle resulted in lower Hounsfield unit measured average $\mathrm{CT}$ value, and with the incensement of CT fat content $\mathrm{CT}$ muscle percentage decreased. The $\mathrm{CT}$ value of intermuscular and subcutaneous fat contents are associated with negative Hounsfield values $(-200--20$ : Holló et al., 2007), but for the evaluation for intramuscular fat, positive Hounsfield values ( $-200-$ +19: Holló et al., 2012, +10 - +20: FonT-I-FuRnols et al., 2014) should also be included in the analysis. The average CT fat content of longissimus was lower $(\sim 1 \%)$ than chemical fat content similarly to previous findings of ANTON et al. (2013). In the present study, the highest intramuscular chemical fat level and CT fat percentage of longissimus muscle was obtained by bulls classified as SEUROP fat grade 1, followed by fat grade 3, and the lowest intramuscular fat level was measured in carcasses with SEUROP fat grade 2.

Table 2 presents the simple correlation matrix of examined traits.

BONNY and co-workers (2016) concluded that SEUROP conformation and fat score have no relationship with eating quality. In our study, carcass traits moderately correlated with each other, but did not relate to longissimus muscle traits. GUZEK and co-workers (2013) described similar findings in Limousin bulls.

USDA marbling traits loosely correlated with intramuscular fat values obtained by CT and Soxhlet method. In a study conducted in Japan (ОкавE et al., 1999), good correlation $(\mathrm{r}=0.8)$ has been reported between intramuscular fat and marbling detected at 6/7th rib. In contrast, weak to modest correlations have been found in Australian studies. Using the AUSMEAT marbling scores, TAYLOR and JoHNSON (1992) reported correlation of 0.32 at the 10/11th rib position. 


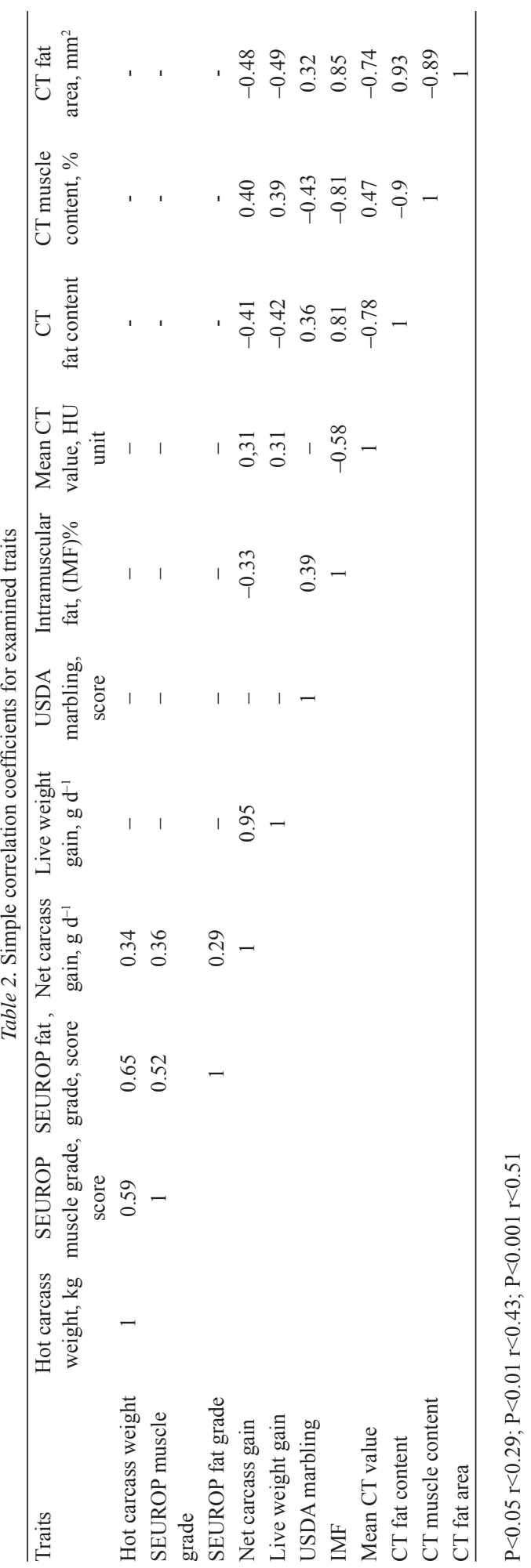


PoLÁK and co-workers (2008) found that the grey value of ultrasound images measured by computer image analysis was significantly correlated with the content of chemical IMF $\mathrm{r}=0.78 ; \mathrm{P}<0.01$, for Slovak Simmental breeds.

The fat percentage and fat area in longissimus muscle on CT-scans closely correlated with chemical fat content $(r=0.81$ and 0.85 , respectively). FrisulLo and co-workers (2010), who used X-ray microcomputed tomography to quantify the intramuscular fat content of beef, have found high correlation coefficient (r) of 0.9 between percentage object volume and IMF content. Similarly to the current experiment, the intramuscular fat levels measured by CT were generally lower compared to values of the chemical percentage method, but the correlation between mentioned methods was significant (Holló et al. 2012). ANTON and coworkers (2013) compared chemical analysis or dissection with CT in order to determine the intramuscular fat and carcass fat content of beef. The correlations were between intramuscular fat (\% from Soxhlet analysis) and CT fat (\%) in musculus longissimus dorsi, and between dissected fat $(\%)$ of the right carcass-half and CT fat (\%) between the 11th and 13 th rib joint of 0.71 and $0.96(\mathrm{P}<0.001)$, respectively. The use of CT to predict eating quality through assessment of intramuscular fat percentage and shear-force of the longissimus lumborum has been also investigated by NAVAJAS and co-workers (2009). KARAMICHOU and co-workers (2006) demonstrated muscle CT density in sheep was correlated to meat quality traits. In the current study negative correlation was detected between CT fat and CT muscle percentage, as well as average $\mathrm{CT}$ value and fat content.

It is important to evaluate correlations between growth rate and marbling traits. The selection for faster growth rate resulted in same carcass weight leaner carcass. Animals are less mature and subsequently have reduced intramuscular fat in muscles. The amount of marbling and growth rate may all vary somewhat independently, cattle breeds with different growth rate compared at same degree of marbling (WHEELER et al., 2005). Generally, fat deposition increases with the increasing time on feed, and increasing the time on feed can improve beef tenderness, due to the effect on marbling (SAMI et al., 2004). Similarly to these findings, both live weight gain and net carcass gain demonstrated a negative association with $\mathrm{CT}$ fat percentage and $\mathrm{CT}$ fat area. On the other hand, a positive association was seen between growth rates and CT muscle percentage. It seems that animals displaying higher muscle growth show reduced development of intramuscular fat during fattening phase.

The coefficient of determination was slightly larger between intramuscular fat and CT fat area than intramuscular fat and CT fat volume $\left(\mathrm{R}^{2}=0.70 \mathrm{v} . \mathrm{R}^{2}=0.67 \mathrm{P}<0.001\right)$ (Table 3 , Fig. 1).

Table 3. Prediction of intramuscular fat content based on cross-sectional CT-images of longissimus muscle from 12 th rib cuts

\begin{tabular}{llc}
\hline & $\mathrm{R}^{2}$ & RMSE \\
\hline CT data & & 1.18 \\
Fat tissue content, $\%$ & 0.62 & 0.90 \\
Fat tissue area, $\mathrm{mm}^{2}$ & 0.70 & 1.15 \\
Fat tissue volume, $\mathrm{mm}^{3}$ & 0.67 & 1.54 \\
Overall density, $\mathrm{HU}$ & 0.36 & \\
\hline
\end{tabular}




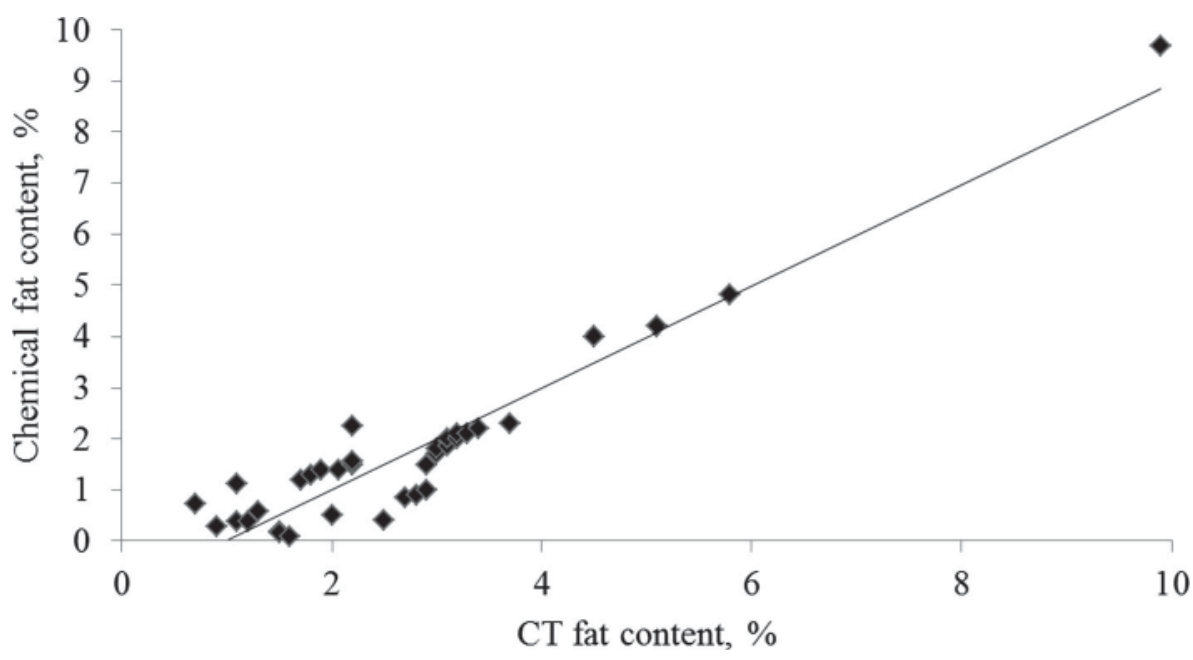

Fig. 1. Relationship between intramuscular (chemical) fat and CT-determined fat contents in longissimus muscle

Moreover, the prediction accuracy is lower based on the percentage of CT fat. PRIETO and co-workers (2010) established prediction models with tissue density values, which offered $\mathrm{R}^{2}$ values of 0.71 and 0.76 . In our study, the inclusion of the average CT density in longissimus muscle in the model to predict intramuscular fat resulted in the lowest coefficient of determination and the highest RMSE value.

Summing up the results, it was demonstrated that CT is a promising technique for the evaluation of intramuscular fat content of meat samples. The prediction accuracy of CT is higher than ultrasound as expected to be. However, more investigations are still needed to enhance the prediction accuracy of this instrument.

\section{Conclusions}

There was no relationship between SEUROP classification and intramuscular fat content of longissimus muscle, yet in contrast, intramuscular fat was highly correlated to CT-data. Intramuscular fat content in longissimus muscle of Simmental bulls decreased with higher growth rate $(\mathrm{r}=-0.40--0.50)$.

This work was supported by the Hungarian Scientific Research Fund (Project 111645).

\section{References}

Anton, I., Zsolnai, A , Holló, I., Repa, I. \& Holló, G. (2013): Effect of thyroglobulin gene polymorphism on the intramuscular fat content in cattle examined by x-ray computed tomography and Soxhlet methods. Arch. Tierzucht., 59, 593-596. 
Bonny, S.P., Legrand, I., Polkinghorne, R.J., Gardner, G.E., Pethick, D.W. \& Hocquette, J.F. (2013): The SEUROP carcase grading system does not predict the eating quality of beef. Abstracts of the 64th Annual Meeting of the European Association for Animal Production, Session 12, Theatre 8, Nantes, France, 96.

Bonny, S.P., Pethick, D.W., Legrand, I., Wierzbicki, J., Allen, P., Farmer, L.J., Polkinghorne, R.J., Hocquette, J.F. \& GARDNER G.E. (2016): European conformation and fat scores have no relationship with eating quality. Animal, 10, 996-1006.

Ender, K. (1997): Künftige Qualitätsanforderungen an Rindfleisch. -in: KolesÁr, R. (Ed.) Proceedings of an International Symposium on Actual and Perspective Tasks in Farm Animal Breeding, RIAP Nitra (Slovakia), Part 2, pp. 27-33.

Ferguson, D.M. (2004): Objective on-line assessment of marbling: a brief review. Aust. J. Exp. Agr., 44, 681-685.

Font-i-Furnols, M., Brun, A., Marti, S., Realini, C.E., Pérez-Juan, M., Gonzalez, J. \& Devant, M. (2014): Composition and intramuscular fat estimation of Holstein bull and steer rib sections by using one or more computed tomography cross-sectional images. Livest. Sci., 170, 210-218.

Frisullo, P., Marino, R., Laverse, J., Albenzio, M. \& Del Nobile, M.A. (2010): Assessment of intramuscular fat level and distribution in beef muscles using X-ray microcomputed tomography. Meat Sci., 85, 250-255.

Guzek, D., GŁąska, D., Pogorzelski, G., Kozań, K., Pietras, J., Konarska, M., Sakowska, A., GŁąski, K., Pogorzelska, E., Barszczewski, J. \& WierzbickA, A. (2013): Variation of meat quality parameters due to conformation and fat class in Limousin bulls slaughtered at 25 to 27 months of age. Asian Austral. J. Anim., $26,716-722$.

Hocquette, J.F., Gondret, F., BaÉza, E., Médale, F., Jurie, C. \& Pethick, D.W. (2010): Intramuscular fat content in meat-producing animals: development, genetic and nutritional control, and identification of putative markers. Animal, 4, 303-309.

Holló, G., Szücs, E., Tözsér, J., Holló, I. \& Repa, I. (2007): Application of X-ray computer tomography (CT) in cattle production. Asian Austral. J. Anim., 20, 1901-1908.

Holló, G., Nuernberg, K., Somogyi, T., Anton, I. \& Holló, I. (2012): Comparison of fattening performance and slaughter value of local Hungarian cattle breeds to international breeds. Arch. Tierzucht, 55, 1-12.

Irie, M. \& Kohira, K. (2012): Simple spot method of image analysis for evaluation of highly marbled beef. Asian Austral. J. Anim., 25, 592-596.

Karamichou, E., Richardson, R.I., Nute, G.R., McLean, K.A. \& Bishop, S.C. (2006): Genetic analyses of carcass composition, as assessed by X-ray computer tomography, and meat quality traits in Scottish Blackface sheep. Anim. Sci., 82, 151-162.

Lee, S., Lohumi, S., Lim, H.S., Gotoh, T., Сно, B.K. \& Jung, S. (2015): Determination of intramuscular fat content in beef using magnetic resonance imaging. J. Fac. Agr. Kyushu U., 60, 157-162.

MANGO ver. 3.8 (2016): Multi-Image Analysis GUI. University of Texas Health Science Center.

Morales, L.E., Griffith, G., Wright, V., Fleming, E., Umberger, W. \& Hoang, N. (2015): Branding fresh food: Who is willing to pay more for beef? Acta Alimentaria, 45, 1-8.

Nade, T.K., Fujta, K.M., Fuji, M.M., Yoshida, M.T., Haryu, T.S., Misumi, S. \& Okumura, T. (2005): Development of X-ray computed tomography for live standing cattle. Anim. Sci. J., 76, 513-517.

Navajas, E.A., Richardson, R.I., Glasbey, C.A., Prieto, N., Ross, D.W., Hyslop, J.J., Simm, G. \& Roehe, R. (2009): Associations between beef density by X-ray computed tomography, intramuscular fat and fatty acid composition: preliminary results. -in: Proceedings of the British Society of Animal Science, 117, Southport, UK.

Nogalski, Z., Wroński, M., Wielgosz-Groth, Z., Purwin, C., Sobczuk Szul, M., Mochol, M. \& Pogorzelska P. (2013): The effect of conformation class (SEUROP system) on the slaughter quality of young crossbred beef bulls and Holstein-Friesians. Ann. Anim. Sci., 13, 121-131.

Okabe, Y., Watanabe, A., Yonemaru, J, Kushibiki, S., Shingu, H. \& Shinoda, M. (1999): The relationships between the grade and meat traits of Japanese black cattle (Wagyu) on the market in Japan. Proc. 45th International Congress of Meat Science and Technology, Yokohama, Japan, pp. 480-481.

Platter, W.J., Tatum, J.D., Belk, K.E., Koontz, S.R., Chapman, P.L. \& Smith G.C. (2005): Effects of marbling and shear force on consumers, willingness to pay for beef strip loin steaks. J. Anim. Sci., 83, 890-899.

Polák, P.J., Mendizabal, A., Blanco, N.E., Roa, E., Krupa, J., Huba, D., PešKovičová, F. \& Oravcová, M. (2008): Prediction of intramuscular fat in live bulls using real-time ultrasound and image analysis. J. Anim. Feed Sci., $17,30-40$.

Polkinghorne, R.J. \& Thompson, J.M. (2010): Meat standards and grading: A world view. Meat Sci., 86, $227-235$. 
Prieto, N., Navajas, E.A., Richardson, R.I., Ross, D.W., Hyslop, J.J., Simm, G. \& Roehe, R. (2010): Predicting beef cuts composition, fatty acids and meat quality characteristics by spiral computed tomography. Meat Sci., 86, $770-779$.

Sami, A.S., Augustini, C. \& Schwarz, F.J. (2004): Effects of feeding intensity and time on feed on performance, carcass characteristics and meat quality of Simmental bulls. Meat Sci., 67, 195-201.

TAYlor, D.G. \& Johnson, E.R. (1992): Visual marbling score and chemical fat content on m. longissimus in beef carcasses. Proc. Australian Society of Animal Production, 19, pp. 71-73.

Thompson, J. (2004): The effects of marbling on flavour and juiciness scores of cooked beef, after adjusting to a constant tenderness. Anim. Prod. Sci., 44, 645-652.

Troy, D.J., Tiwari, B.K. \& Joo, S.T. (2016): Health implications of beef intramuscular fat consumption. Korean J. Food Sci. An., 36, 577-582.

USDA (1997): United States Standards for grades of carcass beef. United States Department of Agriculture, Agricultural Marketing Service, Livestock and Seed Division, Washington, DC.

USDA (2006): Instrument grading systems for beef carcasses. Performance requirements for instrument marbling evaluation (PRIME) II: Implementation and verification of operational procedures. USDA, Agricultural Marketing Service, Livestock and Seed Division, Washington, DC., 3 pages.

Wheeler, L., Cundiff, L.V., Shackelford, S.D. \& Koohmaraie, M. (2005): Characterization of biological types of cattle (Cycle VII), carcase, yield, and longissimus palatability traits. J. Anim. Sci., 83,196-207. 